\title{
A Symbiont-Independent Endo-1,4- $\beta$-Xylanase from the Plant-Parasitic Nematode Meloidogyne incognita
}

\author{
Makedonka Mitreva-Dautova, ${ }^{1}$ Erwin Roze,${ }^{2}$ Hein Overmars, ${ }^{2}$ Leo de Graaff, ${ }^{3}$ Arjen Schots, ${ }^{4}$ \\ Johannes Helder, ${ }^{2}$ Aska Goverse, ${ }^{2}$ Jaap Bakker, ${ }^{2}$ and Geert Smant ${ }^{2}$ \\ ${ }^{1}$ Genome Sequencing Centre, Department of Genetics, Washington University School of Medicine, St. Louis, MO 63108, \\ U.S.A.; ${ }^{2}$ Laboratory of Nematology, ${ }^{3}$ Laboratory of Microbiology, and ${ }^{4}$ Laboratory of Molecular Recognition and Antibody \\ Technology, Wageningen University, Binnenhaven 5, 6709 PD Wageningen, The Netherlands
}

Submitted 31 August 2005. Accepted 20 January 2006.

\begin{abstract}
Substituted xylan polymers constitute a major part of the hemicellulose fraction of plant cell walls, especially in monocotyledons. Endo-1,4- $\beta$-xylanases (EC 3.2.1.8) are capable of hydrolyzing substituted xylan polymers into fragments of random size. Many herbivorous animals have evolved intimate relationships with endosymbionts to exploit their enzyme complexes for the degradation of xylan. Here, we report the first finding of a functional endo-1,4- $\beta$-xylanase gene from an animal. The gene (Mi-xyl1) was found in the obligate plant-parasitic root-knot nematode Meloidogyne incognita, and encodes a protein that is classified as a member of glycosyl hydrolase family 5 . The expression of Mi-xyll is localized in the subventral esophageal gland cells of the nematode. Previous studies have shown that $M$. incognita has the ability to degrade cellulose and pectic polysaccharides in plant cell walls independent of endosymbionts. Including our current data on Mi-xyl1, we show that the endogenous enzyme complex in root-knot nematode secretions targets essentially all major cell wall carbohydrates to facilitate a stealthy intercellular migration in the host plant.
\end{abstract}

Additional keywords: cell-wall-degrading enzyme.

Plant cells have an extracellular matrix known as the cell wall which is a highly organized composite of diverse polysaccharides, proteins, and aromatic compounds (Cosgrove 1997). In current models of the cell wall, its architecture is described as consisting of several independent but interacting structural networks (Carpita and Gibeaut 1993). The primary structural network is made of cellulose microfibrils interlocked by heterogeneous polymeric glycans and xylans. This cellulose/hemicellulose scaffold is embedded in a matrix of pectic polysaccharides, which may be reinforced by covalent interactions with aromatic compounds such as the phenylpropanoids. An important function of plant cell walls is to dictate size and shape of the protoplasts during cell growth and differentiation. To further protect the cell against invading organisms, the cell wall may become impregnated with structural proteins and lignins, or covered with local deposits of callose. Alternatively,

Corresponding author: G. Smant; Telephone: (+31) 317 485254; Fax: (+31) 317 484254; E-mail: geert.smant@wur.nl

GenBank accession number: Mi-xyll, AF224342.

* The $\boldsymbol{e}$-Xtra logo stands for "electronic extra" and indicates the HTML abstract available on-line contains a supplemental figure not included in the print edition. diffusible fragments cleaved from cell wall polysaccharides may act as elicitors of specific disease resistance responses to invading pathogens and parasites (Boudart et al. 1998).

The proportion of hemicellulose in terrestrial plants may exceed $30 \%$ of the total dry weight (Cosgrove 1997). In type II cell walls of the Gramineae and related monocot families, substituted xylans form the main hemicellulose polysaccharide (Carpita 1996), whereas it accounts for only $5 \%$ of the primary cell wall in dicots and noncommelinoid monocots. Endo-1,4$\beta$-xylanases (EC 3.2.1.8) are capable of hydrolyzing the backbone polymers of substituted xylans into smaller pieces of random size (Kulkarni et al. 1999). Presently, most of the endo$1,4-\beta$-xylanases belong to families 10 and 11 in the numerical classification of glycoside hydrolase carbohydrate-active enzymes (CAZy) (Henrissat and Bairoch 1996). However, the glycoside hydrolase families (GHFs) 5, 8, 16, 26, 43, and 62 also include relatively poorly characterized bacterial endo-1,4$\beta$-xylanases. Recently, Larson and associates (2003) resolved the first crystallographic structure of an endo-1,4- $\beta$-xylanase not belonging to either GHF10 or 11 .

There currently are a few reports of plant genes encoding endo-1,4- $\beta$-xylanase activity, and the functions of these enzymes are associated with a variety of developmental processes (Banik et al. 1996; Bih et al. 1999; Chen and Paull 2003; Suzuki et al. 2002). In contrast, endo-1,4- $\beta$-xylanases have been reported in a wide range of microorganisms that typically are associated with the degradation of plant cell walls (Beg et al. 2001). For instance, the hydrolysis of xylan polymers of plant cell walls in ruminants depends on enzymes from endosymbiotic bacteria and fungi (Wubah et al. 1993). Similarly, bacteria and fungi are known to contribute to the endo- $1,4-\beta$-xylanase activity in the digestive tracts of xylophagous wood-boring insects (Brennan et al. 2004). Some bacterial and fungal pathogens of plants also secrete endo-1,4- $\beta$-xylanase, suggesting that it may contribute to the infection process (Walton 1994). Conversely, there also are reports of fungal endo-1,4- $\beta$-xylanases that have an adverse effect on the colonization of the plant because they act as elicitors of a cultivar-specific local hypersensitive response in tomato, tobacco, and pepper plants (Yano et al. 1998).

Here, we report the characterization of the first functional animal endo-1,4- $\beta$-xylanase gene from the southern root-knot nematode Meloidogyne incognita. This enzyme is classified as a member of GHF5. The root-knot nematodes (Meloidogyne spp.) are obligate endoparasites of thousands of different plant species, including both monocotyledons and dicotyledons (Williamson and Hussey 1996). These microscopic worms use a hollow, protrusible stylet to penetrate plant cell walls, release esophageal gland secretions, and withdraw nutrients from the 
plant cell cytoplasm. The initial penetration of the root epidermis takes place in the elongation and differentiation zone, after which the nematode migrates parallel to the vascular bundle through the cortex toward the root tip. In the quiescent center and the apical initial region, the nematode makes a U-turn through the procambium into the vascular cylinder, where it establishes a feeding site (Sijmons et al. 1991). Amazingly, this extensive intercellular migration of the nematode does not inflict any detectable damage to the cells in the cortex and the vascular cylinder. To facilitate this stealthy invasion process, the nematode partially dissolves the middle lamella and the primary cell wall between columns of cells. Stylet secretions are believed to have an important role in this parasitic behavior and, therefore, are the subject of intense study (Davis et al. 2000, 2004). It recently has been discovered that nematodes use cellulases (De Meutter et al. 1998; Gao et al. 2004; Kikuchi et al. 2004; Rosso et al. 1999; Smant et al. 1998; Uehara et al. 2001; Yan et al. 2001), exo-polygalacturonases (Jaubert et al. 2002), and pectate lyases (De Boer et al. 2002; Doyle and Lambert 2002; Popeijus et al. 2000) to facilitate invasion of the host plant. To date, plant cell wall degradation by animal enzymes has been studied in most detail in nematode-plant interactions covering both covalent and noncovalent interactions between cell wall polymers (Qin et al. 2004). Nematodes were the first animals shown to produce cell-wall-degrading enzymes independent of endosymbionts. With our current finding of an endogenous functional endo-1,4- $\beta$-xylanase gene, we show that nematodes have the capacity to degrade the backbones of essentially all major carbohydrate polymers in the (hemi)cellulose and pectin networks in plant cell walls.

\section{RESULTS}

\section{Identification of an endo-1,4- $\beta$-xylanase gene from $M$. incognita.}

Random sequencing of a cDNA library from $M$. incognita preparasitic second-stage juveniles (J2s) generated an expressed sequence tag (EST) of 740 bp with similarity to an endo-1,4- $\beta$ xylanase of Aeromonas cavia (GenBank accession number AAB63573). Further extension of the cDNA sequence at the 5' and $3^{\prime}$ ends revealed a full-length transcript, named MD0915, of 1,220 nucleotides (nt). The largest open reading frame present in MD0915 consisted of 331 amino acids. The first $21 \mathrm{~N}$-terminal amino acids are predicted by the SignalP set for eukaryotic sequences to encode a signal peptide for secretion, with the most likely cleavage site of the signal peptide between $\mathrm{C}_{21}$ and $\mathrm{D}_{22}$. The predicted molecular mass of the mature protein is $34,848 \mathrm{Da}$, with an isoelectric point of 7.69. Two consensus sites for $\mathrm{N}$-linked glycosylation $\left(\mathrm{N}_{319}\right.$ to $\mathrm{T}_{321}$ and
$\mathrm{N}_{323}$ to $\mathrm{T}_{325}$ ) are present close to the carboxy terminus of the open reading frame.

\section{MD0915 encodes a protein that belongs to glycosyl hydrolase family 5 .}

Similarity searches in nonredundant protein databases showed that the largest open reading frame encoded by MD0915 is significantly similar to members of two GHFs (Table 1). The first group (i) of matches (Bit Scores ranging from 169 to 146 , with $E$ values ranging from $\mathrm{e}^{-41}$ to $\mathrm{e}^{-21}$ ) are the (putative) endo- $\beta-1,4$-xylanases of various bacterial origins, which all are classified as members of the GHF 5 in the CAZy database of glycoside hydrolases (Henrissat and Bairoch 1996). The second group (ii) of matches (Bit Scores ranging from 197 to 152 , with $E$ values ranging from $\mathrm{e}^{-49}$ to $\mathrm{e}^{-6}$ ) represents hypothetical protein sequences from genome sequencing projects on various bacteria that are annotated as possible xylandegrading enzymes from the GHF 30 . However, these latter sequences have not been included in the CAZy classification. The level of significance of the matches from groups $i$ and ii are overlapping, which suggested that the protein encoded by MD0915 could be a member of either GHF5 or GHF30. The inferred protein structure of both GHF5 and GHF30 members is an eightfold $\beta-\alpha$ barrel indicating their ancient ancestry. The variety of enzyme activities in GHF5 (i) includes cellulase (EC 3.2.1.4), endo-1,4- $\beta$-xylanase, and a wide range of enzymes with other substrates. The annotation in the second group (ii) of matches derives from one consensus build on five protein sequences (NCBI conserved domain database accession number COG5520). A closer look at the alignment underlying this consensus revealed that three out of five proteins (GenBank accession numbers AAK76863, AAK76864, and CAB13698) actually are classified in CAZy as putative endo-1,4- $\beta$-xylanase members of GHF5, and not of GHF30. Consistent with the original definition of COG5520, the remaining two protein sequences (GenBank accession numbers AAK23733 and AAL23246) underlying the consensus are classified as putative glycosylceramidase members of GHF30. The significance of the similarities between the open reading frame in MD0915 and GenBank accessions numbers AAK76863, AAK76864, and CAB13698 range from $\mathrm{e}^{-49}$ to $\mathrm{e}^{-33}$ in BLAST-P2 searches, whereas the level of significance of the matches with AAK23733 and AAL23246 are in the range of $\mathrm{e}^{-9}$ to $\mathrm{e}^{-5}$. Based on this finding, we conclude that the sequences that match MD0915 belong to two distinct functional groups: the endo$1,4-\beta$-xylanases in GHF5 and, more distantly, the glycosylceramidases in GHF30. Consequently, MD0915 encodes a protein that is classified as a putative endo-1,4- $\beta$-xylanase member of GHF5 and, therefore, is named Mi-xyll.

Table 1. Summary of BLAST-P2 search using Mi-XYL1 as query in $n r$ protein databases of GenBank

\begin{tabular}{|c|c|c|c|c|c|}
\hline Accession no. ${ }^{\mathrm{a}}$ & Source organism & Score $(\text { bits })^{\mathbf{b}}$ & $\mathrm{ID} / \mathrm{sim}^{\mathrm{c}}$ & Annotation $^{d}$ & $\mathrm{CAZy}^{\mathrm{e}}$ \\
\hline \multicolumn{6}{|l|}{ Group i } \\
\hline AAL16415 & Pectobacterium chrysanthemi & 169 & $33 / 52$ & Endo-xylanase & GHF5 \\
\hline AAM40172 & Xanthomonas campestris pv. campestris & 157 & $31 / 50$ & Xylanase & GHF5 \\
\hline AAB 63573 & Aeromonas punctata & 152 & $33 / 51$ & Xylanase D & GHF5 \\
\hline BAB39494 & Ruminococcus albus & 146 & $32 / 49$ & XynC & GHF5 \\
\hline AAN07016 & Bacillus subtilis & 146 & $31 / 51$ & YnF & GHF5 \\
\hline \multicolumn{6}{|l|}{ Group ii } \\
\hline AAK76864 & Clostridium acetobutylicum & 197 & $37 / 52$ & Possible xylan degrading domain (GHF30-like) & nd \\
\hline ZP_00312042 & C. thermocellum & 152 & $31 / 51$ & COG5520: O-Glycosyl hydrolase (GHF30-like) & nd \\
\hline AAK76863 & C. acetobutylicum & 152 & $31 / 49$ & Possible xylan degrading domain (GHF30-like) & nd \\
\hline
\end{tabular}

\footnotetext{
a Primary GenPept accession number (acc. no.) of the hits.

${ }^{b}$ Bit score of the hits in BLAST-P.

${ }^{\mathrm{c}}$ Percentage of identity (ID) and similarity (sim).

d Primary annotation.

${ }^{\mathrm{e}}$ Classification in glycoside hydrolase carbohydrate-active enzymes (CAZy); GHF = glycoside hydrolase family; nd = not determined.
} 
Mi-xyl-1 encodes a functional endo-1,4- $\beta$-xylanase.

$M i-x y l 1$ was expressed as a translational fusion-protein with the maltose binding protein (MBP) malE (approximately 40 $\mathrm{kDa}$ ) in the periplasm of Escherichia coli. The recombinant protein appeared on a Western blot as a single band of approximately $75 \mathrm{kDa}$ (Fig. 1A and B), which is in agreement with the sum of the predicted molecular weight of the mature $\mathrm{Mi}$ XYL1 and the maltose binding protein. Lysates of E. coli expressing the MBP::Mi-XYL1 fusion protein tested positive in a cup plate assay with birch wood xylan (Fig. 1C). A potential effect of the $\mathrm{pH}$ on the activity of MBP::Mi-XYL1 was assessed by measuring the amount of reducing sugars released from birch wood xylan per unit of time within a $\mathrm{pH}$ range from 3.6
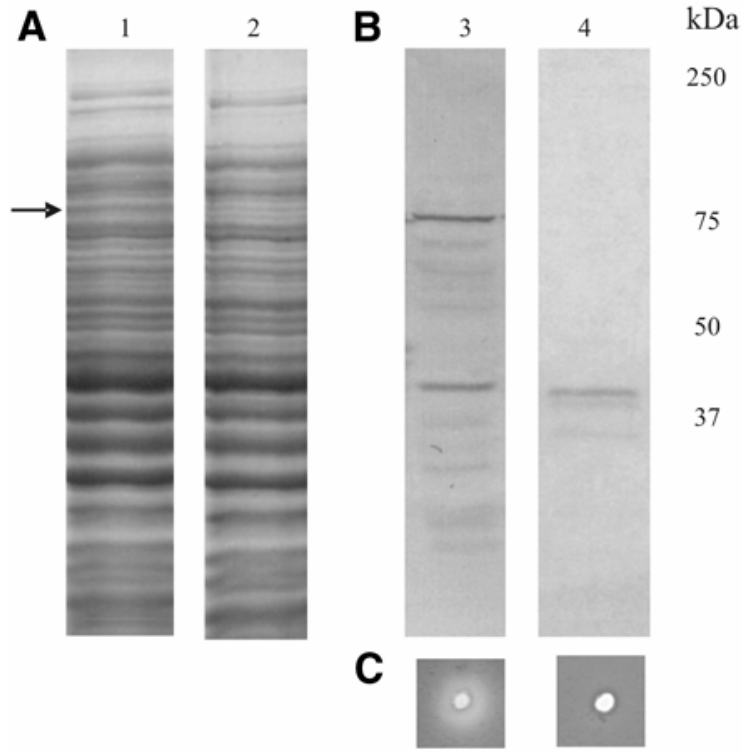

37

C

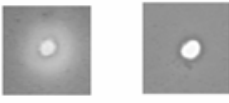

D

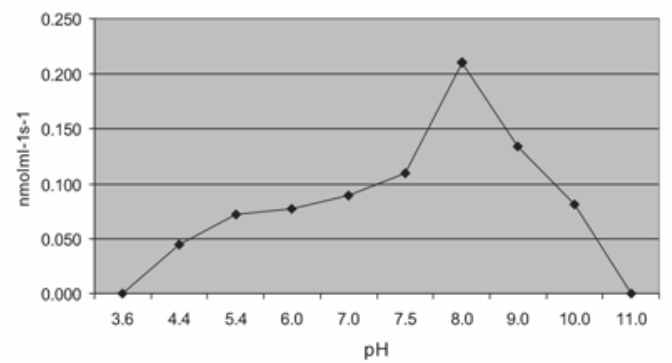

Fig. 1. A, Coomassie brilliant blue-stained sodium dodecyl sulfate polyacrylamide gel of lysate of Escherichia coli cells expressing Mi-xyll from the plasmid $p M A L-p 2$. Lane 1 shows a protein extract from induced $E$. coli cells. The heterologous expression in bacteria was induced for $4 \mathrm{~h}$ at $37^{\circ} \mathrm{C}$ with $0.3 \mathrm{mM}$ isopropylthiogalactoside. Lane 2 shows a protein extract from noninduced $E$. coli cells. B, Detection of MBP::Mi-XYL1 fusion protein in E. coli lysates on Western blot probed with an antibody to the maltose binding protein (MBP). Lane 3 shows the MBP::Mi-XYL1 fusion protein expressed in induced $E$. coli cells. Lane 4 shows the MBP alone in a protein extract from induced $E$. coli cells harboring the empty $p M A L-p 2$ vector. Molecular mass markers are indicated on the right side of the panel. The arrow indicating the MBP::Mi-XYL1 fusion protein is on the left side of the panel. C, A semiquantitative cup plate enzyme activity assay of the MBP::Mi-XYL1 fusion protein using birch wood xylan in agar. Lane 3 shows the activity in a protein extract from $E$. coli cells expressing the MBP::Mi-XYL1 fusion protein from the pMal-p2 plasmid. Lane 4 shows the activity of the MBP protein alone in protein extracts from $E$. coli cells harboring $p M A L-p 2$. D, The $\mathrm{pH}$ effect on the activity of MBP::Mi-XYL1 on birch wood xylan. The effect of the $\mathrm{pH}$ on the activity of MBP::Mi-XYL1 is measured in the release of reducing sugars in nanomol per milliliter per second. to 9 . The highest amount of reducing sugars at $30^{\circ} \mathrm{C}$ with an enzyme/substrate ratio of 1:10 was detected at $\mathrm{pH}$ 8.0, thus revealing the optimum $\mathrm{pH}$ for Mi-XYL1 activity (Fig. 1D). Lysates of bacteria producing the MBP protein from the expression vector pMAL-p2 alone did not produce a halo in the cup plate assays or any detectable level of reducing sugars.

\section{GHF5 cellulases and endoxylanases differ} in $\beta$-sheets $\beta 1$ and $\beta 3$.

All cellulase genes that have been found in $M$. incognita to date also belong to GHF5 (Rosso et al. 1999), and we expected to find sequence similarities between the nematode endoxylanase members and cellulase members of GHF5. Surprisingly, the sequence alignments of Mi-XYL1 and Mi-ENG-1 (GenBank accession number AAD45686), or any other nematode cellulase in GHF5, did not reveal any statistically significant similarities. Hydrophobic cluster analysis subsequently was used to compare the folding patterns of two functional cellulase members of GHF5 (Mi-ENG-1 in M. incognita and endoglucanase $\mathrm{Z}$ in Pectobacterium chrysanthemi, GenBank accession number AAB53151), the best-matching functional endo-1,4- $\beta$ xylanase in GHF5 (P. chrysanthemi, GenBank accession number AAB53151), and Mi-XYL1 (Fig. 2). The alignment of the hydrophobic cluster analysis (HCA) plots was aided by the crystallographic data of the cellulase and the endoxylanase from $P$. chrysanthemi (Protein Data Base [PDB] accessions $1 \mathrm{EGZ}$ and $1 \mathrm{NOF})$. The alignment showed that the overall eightfold $\beta-\alpha$ barrel architecture is conserved in all four protein sequences, which facilitated the identification of two putative active site glutamic acids in the Mi-XYL1 sequence $\left(\mathrm{E}_{158}\right.$ and $E_{246}$ ) flanking $\beta$-sheets $\beta 4$ and $\beta 7$. An asparagine residue directly amino terminal to the putative acid catalyst $\left(\mathrm{E}_{158}\right)$ which is conserved in most members, including the other putative endoxylanases in GHF5, is replaced by serine $\left(\mathrm{S}_{157}\right)$ in MiXYL1. Several independent clones of MD0915 were analyzed at this position to eliminate the possibility of a sequencing error. An alignment of all (putative) endoxylanase members of GHF5 showed that a histidine residue at the carboxy flank in the $\beta 3$-sheet, which is highly conserved in most cellulase members of GHF5, is present only in two endoxylanases of GHF5 (GenBank accessions numbers CAE11246 and CAB13698 from Bacillus spp.). The conserved histidine in the $\beta 3$-sheet of most GHF5 members is replaced with a tryptophan in GHF5 endoxylanases, and resembles at this position GHF10 endoxylanases. The $\beta 3$-sheet in Mi-XYL1, however, includes neither a histidine nor a tryptophan. Furthermore, there is almost an absolute conservation in the amino acid motif $\left(\mathrm{G}_{38} \mathrm{~F}_{39} \mathrm{G}_{40} \mathrm{G}_{41}\right.$ in Mi-XYL1) that makes up the first $\beta$-sheet in the endoxylanase members of the GHF5, which is absent in the cellulase members in this family.

\section{Mi-xyl1 represents an evolutionary outgroup among GHF5 endoxylanases.}

A phylogenetic analysis of all endoxylanase members of GHF5 (Fig. 3) revealed three clusters of closely related sequences separate from the protein Mi-XYL1. The first cluster comprises two nearly identical sequences originating from a genome sequencing project on Clostridium acetobutylicum. The second cluster, with an average maximum likelihood distance of 0.150, includes the sequences from Bacillus subtilis and B. amyloliquefaciens, and two sequences from Aeromonas punctata. B. subtilis and B. amyloliquefaciens are soil-dwelling saprophytes, whereas $A$. punctata occurs in surface and waste water. The third cluster, with an average maximum likelihood distance of 0.368 , includes three sequences from plant-pathogenic bacteria ( $P$. chrysanthemi, GenBank accession numbers AAL16415 and AAB53151; and Xanthomonas campestris, 
GenBank accession number AAM40172). Although the average maximum likelihood distance in the complete dataset is 0.83387, the distances of Mi-XYL1 to the other taxa range from 1.14735 to 1.27548 .

\section{Mi-xyl1 is expressed in the subventral esophageal glands.}

$M i$-xyll transcripts were detected in whole-mount sections of preparasitic J2s of $M$. incognita using digoxigenin-11dUTP-labeled antisense probes. Transcription of the Mi-xyll gene was confined to the two subventral esophageal glands (Fig. 4A). The transcripts were detected within the gland cell lobe, and not in the gland extensions. As positive control, in situ hybridization was performed with sense and antisense probes designed on the subventral esophageal-gland-specific cellulase gene Mi-eng- 1 (Rosso et al. 1999). Labeling of the subventral glands was stronger in the case of Mi-eng-1 (Fig. 4B), indicating a higher transcriptional level compared with $M i$-xyll. In control experiments with sense probes from the Mi-xyll and Mi-eng- 1 gene, no hybridization was detectable in nematode sections (Fig. 4C).

\section{Mi-xyl1 homologs are present in M. javanica.}

DNA blot hybridization using a 311-nt digoxigenin-11dUTP-labeled probe of $M i-x y l l$ revealed two distinct bands in genomic DNA of $M$. incognita (Fig. 5, lanes 1 and 2). The oli- gonucleotide primers used to amplify the probe from nematode cDNA also were used to amplify the same region of the coding sequence from the genomic DNA of $M$. incognita. Restriction analysis with $B a m \mathrm{HI}$ and EcoRI showed that the recognition sites of these enzymes are not present in the region of the genomic sequence of $M i-x y l l$ covered by the probe (data not shown) and, consequently, that the two bands on Southern blot represent two similar but distinct genes. Genomic DNA of five other nematode species also was analyzed for hybridizing bands using the same $M i$-xyll-specific probe. A single hybridizing band was observed in genomic DNA of $M$. javanica digested with EcoRI (Fig. 5, lane 3), whereas two faint bands where observed in genomic DNA restricted with BamHI (Fig. 5, lane 4). No hybridization was observed in genomic DNA from the plant parasites M. hapla, Globodera rostochiensis, and G. pallida and the free-living Caenorhabditis elegans (data not shown).

\section{DISCUSSION}

Xylans and glucans in the hemicellulose fraction of terrestrial plants represent one-third of the total carbon resources in biomass on earth. Herbivorous animals have evolved means to break down these cell wall polymers, either to use them as a carbon source or to gain access to the plant cell cytoplasm. For

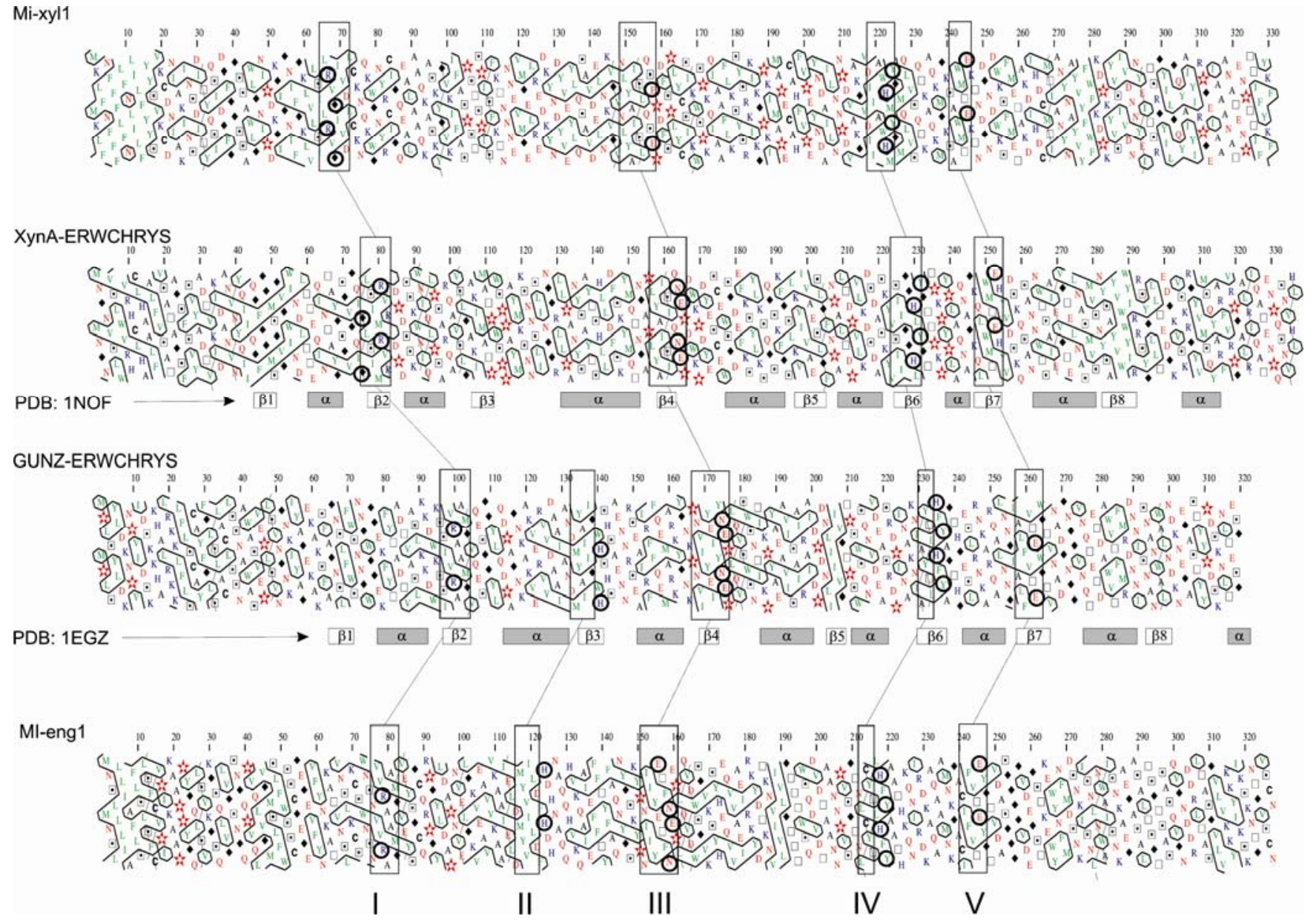

Fig. 2. Alignment of hydrophobic cluster analysis plots of Mi-XYL1 from Meloidogyne incognita and the catalytic domains of a cellulase (Mi-ENG-1) from M. incognita, an endoxylanase (XynA), and a cellulase (GUNZ) from Pectobacterium chrysanthemi showing the overall eightfold $\beta$ - $\alpha$ barrel structure of glycoside hydrolase family (GHF) 5 members. The secondary structure elements from the Protein Data Base accessions of XynA (accession 1NOF) and GUNZ (accession 1EGZ) from P. chrysanthemi are included to optimize the alignment of the hydrophobic cluster analysis plots. The residues encircled by a bold line in boxes I, II, III, IV, and V are described as hallmark features of GHF5 enzymes (Henrissat and Bairoch 1996). Box II, including a histidine putatively conserved in GHF5, is missing in the endo-1,4- $\beta$-xylanases Mi-XYL1 and XynA, whereas the G-F-G-G tetrapeptide that makes up the first $\beta$ sheet in the catalytic domain of XynA is conserved in Mi-XYL1 and in other active endoxylanases of GHF5. 
a long time, it generally was believed that animals were not capable of producing cell-wall-degrading enzymes independent of bacterial or fungal symbionts. This view has been proven wrong as evidence for the production of endogenous cellulases, exopolygalacturonases, and pectate lyases by several different arthropods, mollusks, and nematodes has accumulated. However, no such evidence for the endogenous production of an endo-1,4- $\beta$-xylanase in animals previously has been provided.

Ruminants feeding on monocots make use of endo- $1,4-\beta$ xylanases produced by endosymbiotic bacteria and fungi (e.g., Ruminococcus spp. and Clostridium spp.) (Kim et al. 1999). There still is a broad consensus that these animals are not capable of producing endo-1,4- $\beta$-xylanase themselves. Xylan-degrading activity also has been found in the digestive organs of a variety of other animals, e.g., mollusks (Wang et al. 2003), the rose chafer (Cazemier et al. 1999), beetles (Pitman et al. 2003), cockroaches (Scrivener et al. 1998), termites (Matoub and Rouland 1995), oribatid mites (Hubert et al. 1999), Anoplophora chinensis (Dong et al. 2002), and Antarctic krill (Turkiewicz et al. 2000). Moreover, a cDNA fragment with similarity to endoxylanases was isolated from the digestive tract of the phytophagous beetle Phaedon cochleariae (Girard and Jouanin 1999). The digestive tract of most of these ani- mals is inhabited by cellulolytic and xylolytic microbes, and it is not clear if the origin of cell-wall-degrading enzymes in these animals is endogenous, from symbiotic microorganisms, or both.

In this article, we show for the first time evidence for a functional endo-1,4- $\beta$-xylanase gene $(M i-x y l 1)$ of animal origin. The $M i-x y l l$ gene is transcribed specifically in the subventral esophageal gland cells of the plant-parasite $M$. incognita. Previous studies have shown the expression of other cell-walldegrading enzymes in these single-celled secretory glands, including cellulases, exopolygalacturonases, and pectate lyases. It could be argued that an endosymbiotic eukaryote present in the cytoplasm of the gland cells produces the Mi-xyll transcripts. However, the ultrastructure of the esophageal gland cells of $M$. incognita was studied extensively with electron microscopy and no indications for a eukaryotic endosymbiont living in the cytoplasm of the gland cells were found (Hussey and Mims 1990).

Most members of GHF5 have cellulase activity, including the two cellulases (Mi-eng-1 and Mi-eng-2) (Rosso et al. 1999) previously identified in $M$. incognita. It is noted, however, that some cellulases in GHF5 also may have xylanolytic activity (Gao et al. 2004). The primary amino acid sequence of MiXYL1 shows no significant similarity to Mi-ENG-1 and Mi-

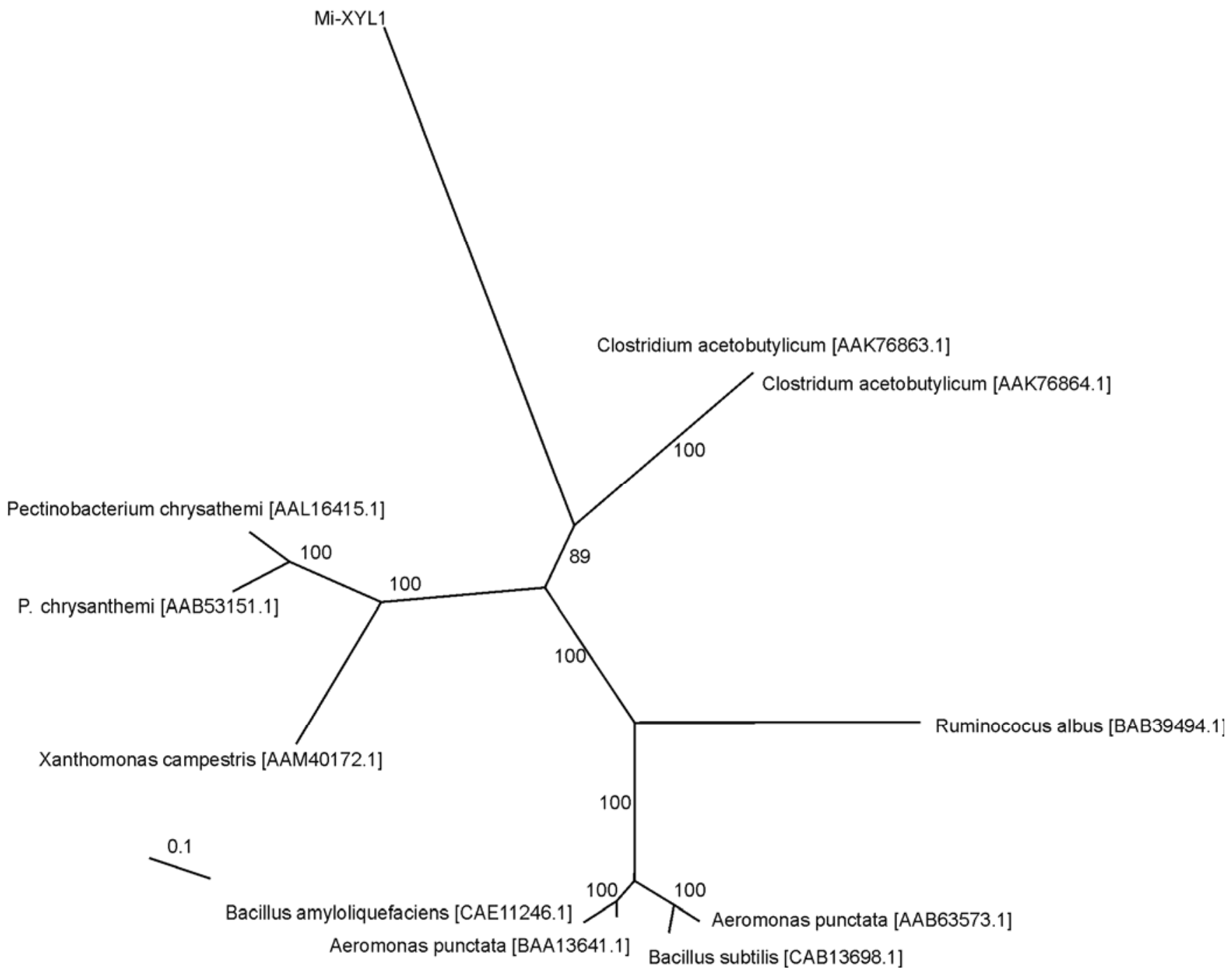

Fig. 3. Phylogenetic analysis of (putative) glycoside hydrolase family (GHF) 5 endo-1,4- $\beta$-xylanases (with primary accession numbers in GenBank between brackets) using maximum likelihood methods. Branch lengths indicate maximum likelihood distance and the relative support for each branching point is indicated at the nodes as a percentage.

Vol. 19, No. 5, 2006 / 525 
ENG-2, or in fact to any of the other cellulases in GHF5. This suggests that, although they are all classified as members of the same GHF5, the cellulases Mi-eng-1, Mi-eng-2, and Mixyll have not arisen from a relatively recent gene duplication in $M$. incognita. Nevertheless, hydrophobic cluster analysis of GHF5 members allowed the identification of four stretches of conserved amino acids in the GHF5 endo-1,4- $\beta$-xylanases and cellulases, including the two glutamic acid residues putatively involved in the active site of the enzymes. A fifth stretch spanning the $\beta_{3} \alpha_{3}$-loop, which was described as a hallmark feature of all GHF5 enzymes, seems not to be conserved in the endo1,4- $\beta$-xylanase members of GHF5. In an attempt to further differentiate the xylanase and cellulase members of GHF5, Larson and associates (2003) suggested that a tryptophan replacing a histidine in this $\beta_{3} \alpha_{3}$-loop could define the xylose specificity

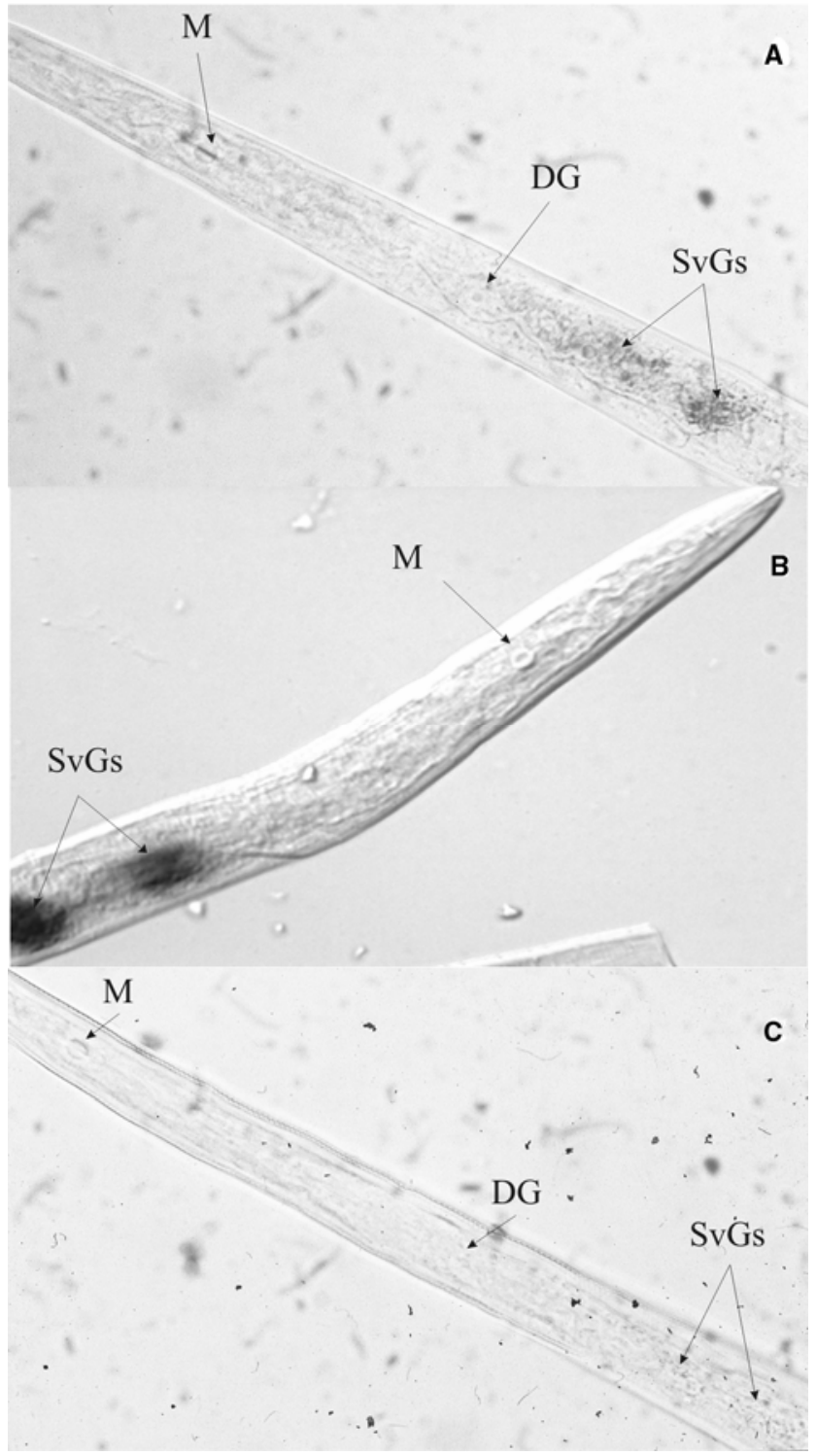

Fig. 4. Whole mount in situ localization of Mi-xyl1 and Mi-eng- 1 transcripts in preparasitic second-stage juveniles of Meloidogyne incognita using digoxigenin-labeled cDNA probes and an alkaline phosphatase-conjugated secondary antibody to digoxigenin. Sections of the nematode incubated with antisense probe designed on A, Mi-xyll and B, Mi-eng-1 showing a specific alkaline phosphatase staining of the subventral esophageal gland cells (SvGs) in anterior sections of nematodes. No specific staining was observed in the dorsal esophageal gland (DG) or in other tissues (M indicates the metacarpus). C, Incubations of nematode sections with sense probe resulted in no specific staining. of both GHF5 and GHF10 endo-1,4- $\beta$-xylanases. However, this tryptophan is not conserved in Mi-XYL1 $\left(\mathrm{S}_{107}\right)$, which makes this hypothesis less likely. The tetra-peptide G-F-G-G that constitutes the first $\beta$-sheet in all endo-1,4- $\beta$-xylanase members of GHF5, including Mi-XYL1, is lacking in other GHF5 members as well as in the xylan-degrading enzymes of all other $\mathrm{GH}$ families and, therefore, may be a more signifying feature of the GHF5 endo-1,4- $\beta$-xylanases. For its greater evolutionary distance to all other GHF5 endo-1,4- $\beta$-xylanase members, Mi-XYL1 may serve as an outgroup to identify the key amino acids for GHF5 type of endo-1,4- $\beta$-xylanase activity. Experiments with site-directed mutagenesis of these amino acid residues in GHF5 endo-xylanases currently are being undertaken in our laboratory and may shed light on the basis of substrate specificity of GHF5 enzymes.

The bacterial endo-1,4- $\beta$-xylanase members of GHF5 all are multidomain proteins, including a catalytic domain of approximately 280 amino acids and a putative C-terminal carbohydrate binding module of approximately 90 amino acids. In contrast, Mi-XYL1 consists only of a catalytic domain of approximately 280 amino acids and, in that sense, it better reflects the topology of most GHF11 members. Nematode cellulases often occur in two nearly identical types, in which presence or absence of the ancillary cellulose-binding domain is the only significant difference (Smant et al. 1998). The second band that appeared on Southern blot of $M$. incognita genomic DNA

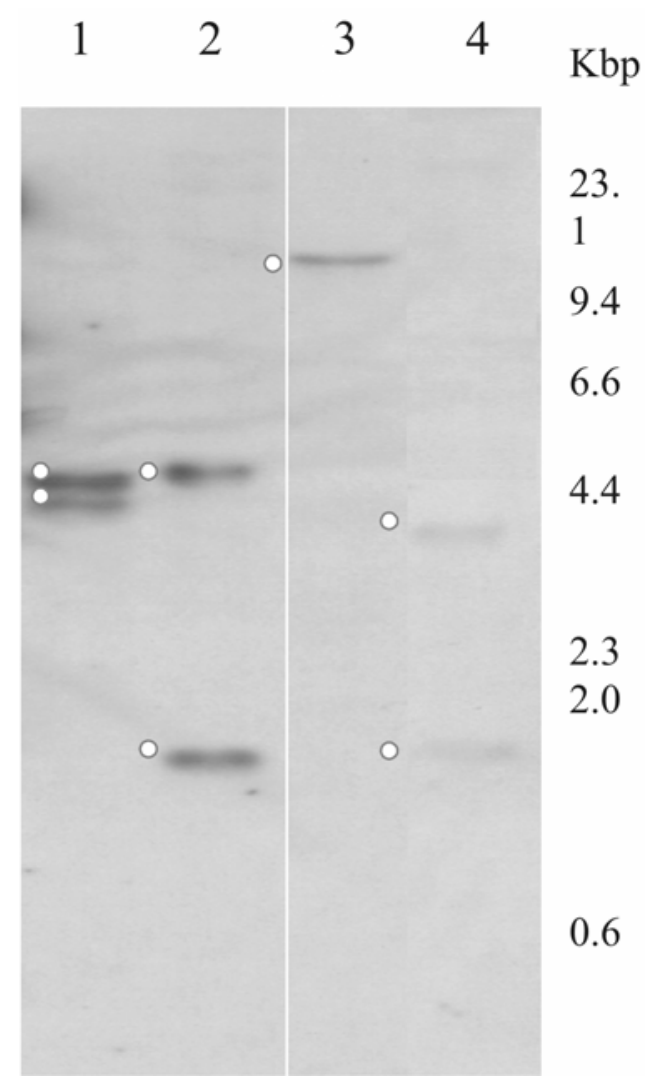

Fig. 5. Southern blot of Meloidogyne incognita and M. javanica genomic DNA probed with $M i$-xyll. Genomic DNA from $M$. incognita (lanes 1 and 2) and $M$. javanica (lanes 3 and 4) was digested with EcoRI and BamHI and hybridized with a digoxygenin-dUTP-labeled probe from $M i$-xyll on a nylon membrane. Two hybridizing bands were observed in $M$. incognita genomic DNA (lanes 1 and 2). One band was observed in EcoRI-digested $M$. javanica genomic DNA (lane 3); whereas, in BamHI-digested genomic DNA, two faint bands were detected (lane 4), indicating the presence of at least one homologous gene in $M$. javanica with a possible internal BamHI site. The DNA size markers are indicated on the right side of the panel, and the white dots indicate positions of the bands. 
probed with $M i-x y l l$ may represent a copy of the gene that includes a carbohydrate-binding module. Preliminary results from an ongoing EST project on the plant parasite $M$. chitwoodi show that this root-knot nematode species has at least one similar endo-1,4- $\beta$-xylanase, including a putative xylan-binding domain (E. Roze, personal communication).

M. incognita is a polyphagous parasite of approximately 700 different plant species, both monocotyledons and dicotyledons. The polymer constitution of the cell wall in each of these host plants varies extensively, thus requiring great flexibility in the substrate specificity of the enzymes in nematode stylet secretions. Southern blot analysis revealed the presence of a homologue of $M i-x y l 1$ in the related root-knot nematode species $M$. javanica, which also thrives on both monocots and dicots; whereas, in M. hapla - a specialist of dicots - the probe failed to produce a hybridizing band. Database searches revealed 2 matching ESTs out of 7,587 from $M$. javanica with approximately $96 \%$ identity in $500 \mathrm{nt}$ (GenBank accession numbers CF350477 and CF350376), 1 match out of 12,218 ESTs from M. chitwoodi (GenBank accession number CB931318), and one short matching element with $86 \%$ identity in $50 \mathrm{nt}$ in 2 ESTs out of 5,018 from $M$. arenaria (GenBank accession numbers CF357210 and CF357155). No matches with $M i$-xyll were found in the 24,452 ESTs that currently are available from $M$. hapla (data not shown). Putative endo-1,4- $\beta$-xylanases also seem to be absent in other nematode species that parasitize dicotyledons only. Although these datasets are limited, we hypothesize for further studies that the production of endo-1,4$\beta$-xylanases in plant-parasitic nematodes is correlated with parasitism on monocots.

Endo-1,4- $\beta$-xylanases are thought to have an essential role in the virulence of bacterial and fungal pathogens of monocots (Walton 1994). Several studies involving targeted gene disruption, however, have not shown that endo-1,4- $\beta$-xylanases are required for the pathogenicity of these plant-pathogens (Gomez Gomez et al. 2002; Keen et al. 1996; Ray et al. 2000; Wu et al. 1997). Attempts to develop similar gene disruption methods for plant-parasitic nematodes in order to assess the role of cellwall-degrading enzymes in parasitism have been fruitless. However, recent developments to knock down genes by RNA interference in other plant-parasitic nematodes currently are being adopted to $M$. incognita (Fanelli et al. 2005; Rosso et al. 2005; Urwin et al. 2002), and these methods may provide information about the influences of endo-1,4- $\beta$-xylanases and other cell-wall-degrading enzymes on the host plant range of plantparasitic nematodes.

\section{MATERIALS AND METHODS}

\section{Nematodes.}

$M$. incognita was propagated on greenhouse cultures of tomato cv. Moneymaker at 20 to $25^{\circ} \mathrm{C}$. Eggs were harvested approximately 12 weeks after inoculation using a $0.5 \%$ (wt/vol) $\mathrm{NaOCl}$-solution (Hussey and Barker 1973). Freshly hatched J2s were collected from eggs on a cotton wool filter, purified using $70 \%$ (wt/vol) sucrose, and stored at $-80^{\circ} \mathrm{C}$ until further processing.

\section{Cloning of Mi-xyl1.}

A partial DNA sequence, named MD0915, was generated by random single-pass $5^{\prime}$ end sequencing of approximately 1,000 clones from a cDNA library constructed by Dautova and associates (2001). MD0915 exhibited some similarity to bacterial xylanases; therefore, its sequence was extended at the $3^{\prime}$ end by sequencing from the universal SP6 priming site upstream, using the clone from which the initial sequence originated. The open reading frame included in the complete insert of the clone showing the similarity with xylanases lacked a start codon, and further amplification reactions were performed to extend the $5^{\prime}$ end of the cDNA sequence. For this purpose, a vector-specific forward primer (5'-ATATCTGCAGAATTCGC TAG-3') and an internal reverse primer (5'-GAGCACATTCG GGTGCCA-3') were combined with a plasmid prep of the cDNA library in a polymerase chain reaction (PCR) using $P$ wo DNA-polymerase according to the manufacturer's protocol (Roche Molecular Diagnostics, Indianapolis, IN, U.S.A.).

\section{DNA sequence analysis.}

Sequencing reactions were performed using the ThermoSequenase fluorescent-labeled primer cycle sequencing kit with 7-deaza-dGTP (Amersham-Pharmacia, Buckinghamshire, U.K.). Basic Local Alignment Search Tool algorithm (BLASTP2) at the National Center for Biotechnology Information (NCBI) was used to compare the deduced protein sequence with the nonredundant sequence database of GenBank (03262005). The presence of an N-terminal signal peptide for secretion was predicted at the Signal-P server (Bendtsen et al. 2004).

\section{In situ hybridization microscopy.}

Linear amplification was used to obtain digoxigenin-11dUTP-labeled sense and antisense cDNA probes according to the manufacturer's protocol (Roche Molecular Diagnostics). The probes were amplified from nucleotide region 625 to $1,095 \mathrm{nt}$ of $M i$-xyll using the primers 5'-TTATGGCACCCGA ATGTGC-3' and 5'-CTGTGATGCACACTTAACG-3' in two separate reactions (De Boer et al. 1998). Sense and antisense probes (nucleotides 83 to 410 ) of Mi-eng-1 were amplified using the primers 5'-TTGGATCCGCTGCTCCTCCATATGG-3' and 5'-GAGCATTGTGGTCGTGAAAGTC-3'. Freshly hatched nematodes were fixed overnight in $2 \%$ (wt/vol) paraformaldehyde and cut into three to four pieces. Alkaline phosphatase activity was detected with X-phosphate and 4-nitrobluetetrazoliumchloride (Roche Molecular Diagnostics). The juveniles were examined using differential interference contrast microscopy (Leica, Deerfield, IL, U.S.A.).

\section{Heterologous expression in $\boldsymbol{E}$. coli.}

The sequence (nucleotides 117 to 1,045 ) encoding the mature protein of $M i-x y l l$ was amplified with $P$ wo DNA-polymerase using oligonucleotide primers 5'-GTCGACGAATTCG ATAATATAGCAAAAATAAATTCTG-3' and $5^{\prime}$-CAAGCTTG GATCCCCTAAAATTTATAGAATATTGTTG-3' according to the manufacturer's protocol. These primers introduced EcoRI and BamHI restriction sites (underlined) at the $5^{\prime}$ and $3^{\prime}$ ends, respectively, of the cDNA sequence to facilitate cloning into the pMAL-p2 expression vector (New England Biolabs, Beverly, MA, U.S.A.). Induction of expression and analysis of the recombinant protein was performed according to the manufacturer.

\section{DNA blot analysis.}

Genomic DNA was isolated from J2s with alkaline/sodium dodecyl sulfate (SDS) lysis and phenol/chloroform extraction (Yan et al. 1998) and blotted on a positively charged nylon membrane (Roche Molecular Diagnostics). A cDNA probe was synthesized from the 172-to-483-nt region of Mi-xyll using primers 5'-GGTGGTTCTAGTGCTTGG-3' and 5'-AATTCAT CAACAGCAGATTG-3', and digoxigenin-11-dUTP in a PCR (Roche Molecular Diagnostics). Prehybridization (in DIG Easy $\mathrm{Hyb}$ at $38^{\circ} \mathrm{C}$ for $30 \mathrm{~min}$ ), hybridization (in DIG Easy Hyb at $38^{\circ} \mathrm{C}$ overnight), stringency washes (in $0.1 \%$ [wt/vol] SSC [1× $\mathrm{SSC}$ is $0.15 \mathrm{M} \mathrm{NaCl}$ plus $0.015 \mathrm{M}$ sodium citrate] and $0.1 \%$ [wt/vol] SDS at $68^{\circ} \mathrm{C}$ ), and immunodetection were performed 
as recommended by the manufacturer (Roche Molecular Diagnostics).

\section{Enzyme activity assays.}

A semiquantitative cup plate assay with birch wood xylan (Sigma, Zwijndrecht, The Netherlands) was used to determine the specific hydrolase activity of the MBP::Mi-XYL1 fusion protein (Keen et al. 1996). The effect of $\mathrm{pH}$ on enzyme activity was determined by measuring the release of reducing sugars (Bailey et al. 1992). For this purpose, birch wood xylan was suspended at a concentration of $1 \%(\mathrm{wt} / \mathrm{vol})$ in $0.05 \mathrm{M}$ buffers based on acetate ( $\mathrm{pH} 3.6$ to 5.4), phosphate ( $\mathrm{pH} 6.0$ to 7.0 ), Tris/HCl ( $\mathrm{pH} 7.0$ to 9.0 ), or carbonate bicarbonate ( $\mathrm{pH} 10.0$ to 11.0$)$. The buffered substrate $(0.9 \mathrm{ml})$ was incubated with $E$. coli lysates harboring either the $M i-x y l 1$ fusion gene or the empty vector $(0.1 \mathrm{ml})$ for $24 \mathrm{~h}$ at $30^{\circ} \mathrm{C}$. Aliquots of $0.2 \mathrm{ml}$ were boiled with $0.3 \mathrm{ml}$ of dinitrosalicylic acid to determine the amount of reducing sugars. Each sample was diluted five times prior to measurement at $540 \mathrm{~nm}$ using a Shimadzu UV-160 recording spectrophotometer (Shimadzu Corp., Kyoto, Japan) with the monomer D-xylose as standard. The absorbance was converted to activities expressed as nanomol of reducing sugars released in $1 \mathrm{ml}$ for a time period of $1 \mathrm{~s}$.

\section{HCA.}

HCA plots were made using the program HCA-PLOT (V3.0; Doriane, Le Chesnay, France). In these plots, the amino acid sequence of the proteins was drawn on a duplicated helical net using the standard one-letter code, except for P, G, T and $\mathrm{S}$, which were represented by stars, diamonds, squares and pointed stars, respectively. Clusters of hydrophobic residues (V, I, L, F, W, M, and Y) were drawn automatically on the bidimensional helical representation. Analysis of the plots was performed as described in the results (Lemesle-Varloot et al. 1990). The resolved protein structures of both an endoglucanase (PDB accession 1EGZ) and a xylanase (PDB accession 1 NOF) from $P$. chrysanthemi were used as coordinating templates for the HCA plots.

\section{Phylogenetic analysis.}

A BLAST-P2 run was executed on the nonredundant database (26032005) of NCBI using the open reading frame encoded by Mi-xyll as query. All matching sequences from the output with an E value lower than $1 \mathrm{e}^{-5}$ and classified as GHF5 in CAZy subsequently were used to construct phylogenetic trees based on maximum parsimony (ProtPars in Phylip; Pasteur Institute, Paris) and maximum likelihood (Puzzle) principles. An initial alignment of the matching sequences was made in ClustalW (version 1.8; EBI, Cambridge, U.K.). The alignment was optimized by removing unambiguously aligned positions and gaps. A character set, including a total of 266 amino acid residues for each taxon, was used to infer the trees. For maximum parsimony analysis, the character set was jumbled seven times and relative support for the nodes was assessed using 1,000 bootstrap replicates with 13 random number seeds. For the maximum likelihood analysis, trees were inferred using the BLOSUM62 model of substitution with 1,000 quartet puzzling steps. Three models of rate heterogeneity were used: uniform, two rate (one variable and one invariable), and gamma distributed.

\section{ACKNOWLEDGMENTS}

We thank J. T. Jones from the Scottish Crop Research Institute for critically reading the manuscript. The work was supported by European Union grants NONEMA (QLK5-1999-1501) and DREAM (QLRT-1999-1462), and by the VENI-VIDI-VICI program of the Dutch Science Foundation (NWO).

\section{LITERATURE CITED}

Bailey, M. J., Biely, P., and Poutanen, K. 1992. Interlaboratory testing of methods for assay of xylanase activity. J. Biotechnol. 23:257-270.

Banik, M., Garrett, T. P. J., and Fincher, G. B. 1996. Molecular cloning of cDNAs encoding (1-4)-beta-xylan endohydrolases from the aleurone layer of germinated barley (Hordeum vulgare). Plant Mol. Biol. 31:1163-1172.

Beg, Q. K., Kapoor, M., Mahajan, L., and Hoondal, G. S. 2001. Microbial xylanases and their industrial applications: a review. Appl. Microbiol. Biotechnol. 56:326-338.

Bendtsen, J. D., Nielsen, H., Von Heijne, G., and Brunak, S. 2004. Improved prediction of signal peptides: SignalP 3.0. J. Mol. Biol. 340:783-795

Bih, F. Y., Wu, S. S. H., Ratnayake, C., Walling, L. L., Nothnagel, E. A., and Huang, A. H. C. 1999. The predominant protein on the surface of maize pollen is an endoxylanase synthesized by a tapetum mRNA with a long 5' leader. J. Biol. Chem. 274:22884-22894.

Boudart, G., Lafitte, C., Barthe, J. P., Frasez, D., and EsquerreTugaye, M. T. 1998. Differential elicitation of defense responses by pectic fragments in bean seedlings. Planta 206:86-94.

Brennan, Y., Callen, W. N., Christoffersen, L., Healey, S., Keller, M., Li, K., Palackal, N., Wells, S., Hazlewood, G. P., Mathur, E. J., Short, J. M., Robertson, D. E., Steer, B. A., Hernandez, M., Tamayo, G., Sittenfeld, A., Dupree, P., and Goubet, F. 2004. Unusual microbial xylanases from insect guts. Appl. Environ. Microbiol. 70:3609-3617.

Carpita, N. C. 1996. Structure and biogenesis of the cell walls of grasses. Annu. Rev. Plant Physiol. Plant Mol. Biol. 47:445-476.

Carpita, N. C., and Gibeaut, D. M. 1993. Structural models of primary cell walls in flowering plants: consistency of molecular structure with the physical properties of the walls during growth. Plant J. 3:1-30.

Cazemier, A. E., Verdoes, J. C., Van Ooyen, A. J. J., and Op den Camp, H. J. M. 1999. Molecular and biochemical characterization of two xylanase-encoding genes from Cellulomonas pachnodae. Appl. Environ. Microbiol. 65:4099-4107.

Chen, N. J., and Paull, R. E. 2003. Endoxylanase expressed during papaya fruit ripening: Purification, cloning and characterization. Funct. Plant Biol. 30:433-441.

Cosgrove, D. J. 1997. Assembly and enlargement of the primary cell wall in plants. Annu. Rev. Cell Dev. Biol. 13:171-201.

Dautova, M., Rosso, M. N., Abad, P., Gommers, F. J., Bakker, J., and Smant, G. 2001. Single pass cDNA sequencing-a powerful tool to analyse gene expression in preparasitic juveniles of the southern rootknot nematode Meloidogyne incognita. Nematology 3:129-139.

Davis, E. L., Hussey, R. S., Baum, T. J., Bakker, J., Schots, A., Rosso, M.N., and Abad, P. 2000. Nematode parasitism genes. Annu. Rev. Phytopathol. 38:365-396.

Davis, E. L., Hussey, R. S., and Baum, T. J. 2004. Getting to the roots of parasitism by nematodes. Trends Parasitol. 20:134-141.

De Boer, J. M., Yan, Y., Smant, G., Davis, E. L., and Baum, T. J. 1998. Insitu hybridization to messenger RNA in Heterodera glycines. J. Nematol. 30:309-312

De Boer, J. M., McDermott, J. P., Davis, E. L., Hussey, R. S., Popeijus, H., Smant, G., and Baum, T. J. 2002. Cloning of a putative pectate lyase gene expressed in the subventral esophageal glands of Heterodera glycines. J. Nematol. 34:9-11.

De Meutter, J., Tytgat, T., Van der Schueren, E., Smant, G., Schots, A., Coomans, A., Van Montagu, M., and Gheysen, G. 1998. Cloning of two endoglucanase genes from Heterodera schachtii. Meded. Facult. Landbouwwet. Toegep. Biol. Wetens. Univ. Gent 63:619-623.

Dong, Y. M., Yin, Y. P., Cao, Y. Q., and He, Z. B. 2002. Purification and properties of xylanase from Anoplophora chinensis (Forster). Acta Entomol. Sin. 45:165-169.

Doyle, E. A., and Lambert, K. N. 2002. Cloning and characterization of an esophageal-gland-specific pectate lyase from the root-knot nematode Meloidogyne javanica. Mol. Plant-Microbe Interact. 15:549-556.

Fanelli, E., Di Vito, M., Jones, J. T., and De Giorgi, C. 2005. Analysis of chitin synthase function in a plant parasitic nematode, Meloidogyne artiella, using RNAi. Gene 349:87-95.

Gao, B. L., Allen, R., Davis, E. L., Baum, T. J., and Hussey, R. S. 2004 Developmental expression and biochemical properties of a beta-1,4endoglucanase family in the soybean cyst nematode, Heterodera glycines. Mol. Plant Pathol. 5:93-104

Girard, C., and Jouanin, L. 1999. Molecular cloning of cDNAs encoding a range of digestive enzymes from a phytophagous beetle, Phaedon cochleariae. Insect Biochem. Mol. Biol. 29:1129-1142.

Gomez Gomez, E., Ruiz Roldan, M. C., Di Pietro, A., Roncero, M. I. G., and Hera, C. 2002. Role in pathogenesis of two endo-beta-1,4-xylanase genes from the vascular wilt fungus Fusarium oxysporum. Fungal Genet. Biol. 35:213-222. 
Henrissat, B., and Bairoch, A. 1996. Updating the sequence-based classification of glycosyl hydrolases. Biochem. J. 316:695-696.

Hubert, J., Sustr, V., and Smrz, J. 1999. Feeding of the oribatid mite Scheloribates laevigatus (Acari: Oribatida) in laboratory experiments. Pedobiologia 43:328-339.

Hussey, R. S., and Barker, K. R. 1973. A comparison of methods of collecting inocula of Meloidogyne spp., including a new technique. Plant Dis. Rep. 57:1025-1028.

Hussey, R. S., and Mims, C. W. 1990. Ultrastructure of esophageal glands and their secretory granules in the root-knot nematode Meloidogyne incognita. Protoplasma 156:9-18.

Jaubert, S., Laffaire, J. B., Abad, P., and Rosso, M. N. 2002. A polygalacturonase of animal origin isolated from the root-knot nematode Meloidogyne incognita. FEBS (Fed. Eur. Biol. Soc.) Lett. 522:109-112.

Keen, N. T., Boyd, C., and Henrissat, B. 1996. Cloning and characterization of a xylanase gene from corn strains of Erwinia chrysanthemi. Mol. Plant-Microbe Interact. 9:651-657.

Kikuchi, T., Jones, J. T., Aikawa, T., Kosaka, H., and Ogura, N. 2004. A family of glycosyl hydrolase family 45 cellulases from the pine wood nematode Bursaphelenchus xylophilus. FEBS (Fed. Eur. Biol. Soc.) Lett. 572:201-205.

Kim, W. Y., Ha, J. K., Han, I. K., Lee, S. S., Shin, K. J., and Kim, W. Y. 1999. The rumen ecosystem: as a fountain source of noble enzymesreview. Asian-Aust. J. Anim. Sci. 12:988-1001.

Kulkarni, N., Shendye, A., and Rao, M. 1999. Molecular and biotechnological aspects of xylanases. FEMS (Fed. Eur. Microbiol. Soc.) Microbiol. Rev. 23:411-456.

Larson, S. B., Day, J., de la Rosa, A. P. B., Keen, N. T., and McPherson, A. 2003. First crystallographic structure of a xylanase from glycoside hydrolase family 5: Implications for catalysis. Biochemistry 42:84118422.

Lemesle-Varloot, L., Henrissat, B., Gaboriaud, C., Bissery, V., Morgat, A., and Mornon, J. P. 1990. Hydrophobic cluster analysis: procedures to derive structural and functional information from 2-D-representation of protein sequences. Biochimie 72:555-574.

Matoub, M., and Rouland, C. 1995. Purification and properties of the xylanases from the termite Macrotermes bellicosus and its symbiotic fungus Termitomyces spp. Comp. Biochem. Physiol. B 112:629-635.

Pitman, A. J., Jones, E. B. G., and Oevering, P. 2003. An overview of the biology of the wharf borer beetle (Nacerdes melanura L., Oedemeridae) a pest of wood in marine structures. Biofouling 19:239-248.

Popeijus, H., Overmars, H., Jones, J., Blok, V., Goverse, A., Helder, J., Schots, A., Bakker, J., and Smant, G. 2000. Enzymology-degradation of plant cell walls by a nematode. Nature 406:36-37.

Qin, L., Kudla, U., Roze, E. H. A., Goverse, A., Popeijus, H., Nieuwland, J., Overmars, H., Jones, J. T., Schots, A., Smant, G., Bakker, J., and Helder, J. 2004. Plant degradation: A nematode expansin acting on plants. Nature 427:30.

Ray, S. K., Rajeshwari, R., and Sonti, R. V. 2000. Mutants of Xanthomonas oryzae pv. oryzae deficient in general secretory pathway are virulence deficient and unable to secrete xylanase. Mol. Plant-Microbe Interact. 13:394-401.

Rosso, M. N., Favery, B., Piotte, C., Arthaud, L., De Boer, J. M., Hussey, R. S., Bakker, J., Baum, T. J., and Abad, P. 1999. Isolation of a cDNA encoding a beta-1,4-endoglucanase in the root-knot nematode Meloi- dogyne incognita and expression analysis during plant parasitism. Mol. Plant-Microbe Interact. 12:585-591.

Rosso, M. N., Dubrana, M. P., Cimbolini, N., Jaubert, S., and Abad, P. 2005. Application of RNA interference to root-knot nematode genes encoding esophageal gland proteins. Mol. Plant-Microbe Interact. 18:615.

Scrivener, A. M., Watanabe, H., and Noda, H. 1998. Properties of digestive carbohydrase activities secreted by two cockroaches, Panesthia cribrata and Periplaneta americana. Comp. Biochem. Physiol. B 119:273-282.

Sijmons, P. C., Grundler, F. M. W., Von Mende, N., Burrows, P. R., and Wyss, U. 1991. Arabidopsis thaliana as a new model host for plantparasitic nematodes. Plant J. 1:245-254.

Smant, G., Stokkermans, J. P. W. G., Yan, Y., De Boer, J. M., Baum, T. J., Wang, X., Hussey, R. S., Gommers, F. J., Henrissat, B., Davis, E. L., Helder, J., Schots, A., and Bakker, J. 1998. Endogenous cellulases in animals: Isolation of $\beta$-1,4-endoglucanase genes from two species of plant-parasitic cyst nematodes. Proc. Natl. Acad. Sci. U.S.A. 95:49064911.

Suzuki, M., Kato, A., Nagata, N., and Komeda, Y. 2002. A xylanase, AtXyn1, is predominantly expressed in vascular bundles, and four putative xylanase genes were identified in the Arabidopsis thaliana genome. Plant Cell Physiol. 43:759-767.

Turkiewicz, M., Kalinowska, H., Zielinska, M., and Bielecki, S. 2000. Purification and characterization of two endo-1,4-beta-xylanases from Antarctic krill, Euphausia superba Dana. Comp. Biochem. Physiol. B 127B:325-335.

Uehara, T., Kushida, A., and Momota, Y. 2001. PCR-based cloning of two beta-1,4-endoglucanases from the root-lesion nematode Pratylenchus penetrans. Nematology 3:335-341.

Urwin, P. E., Lilley, C. J., and Atkinson, H. J. 2002. Ingestion of doublestranded RNA by preparasitic juvenile cyst nematodes leads to RNA interference. Mol. Plant-Microbe Interact. 15:747-752.

Walton, J. D. 1994. Deconstructing the cell wall. Plant Physiol. 104:11131118

Wang, J., Ding, M., Li, Y. H., Chen, Q. X., Xu, G. j., and Zhao, F. k. 2003. A monovalent anion affected multi-functional cellulase EGX from the mollusca, Ampullaria crossean. Prot. Express. Purif. 31:108-114.

Williamson, V. M., and Hussey, R. S. 1996. Nematode pathogenesis and resistance in plants. Plant Cell 8:1735-1745.

Wu, S. C., Ham, K. S., Darvill, A. G., and Albersheim, P. 1997. Deletion of two endo- $\beta-1,4$-xylanase genes reveals additional isozymes secreted by the rice blast fungus. Mol. Plant-Microbe Interact. 10:700-708.

Wubah, D. A., Akin, D. E., and Borneman, W. S. 1993. Biology, fiber-degradation, and enzymology of anaerobic zoosporic fungi. Crit. Rev. Microbiol. 19:99-115.

Yan, Y., Smant, G., Stokkermans, J., Qin, L., Helder, J., Baum, T., Schots, A., and Davis, E. 1998. Genomic organization of four $\beta$-1,4-endoglucanase genes in plant-parasitic cyst nematodes and its evolutionary implications. Gene 220:61-70.

Yan, Y., Smant, G., and Davis, E. L. 2001. Functional screening yields a new beta-1,4-endoglucanase gene from Heterodera glycines that may be the product of recent gene duplication. Mol. Plant-Microbe Interact. 14:63-71.

Yano, A., Suzuki, K., Shinshi, H., and Uchimiya, H. 1998. Induction of hypersensitive cell death by a fungal protein in cultures of tobacco cells. Mol. Plant-Microbe Interact. 11:115-123. 